\title{
LA NULIDAD DIFERIDA DE LAS LEYES EN CASO DE OMISIÓN DE INFORMES AUTONÓMICOS PRECEPTIVOS
}

\author{
Miquel Pons Portella \\ Abogado
}

\section{RESUMEN}

En el ordenamiento jurídico español, la nulidad se relaciona con la idea de invalidez radical y retroactiva. Sin embargo, sobre todo en estos últimos años, el Tribunal Constitucional viene haciendo uso de la posibilidad de retrasar la eficacia de una declaración de inconstitucionalidad, de modo que una ley nula siga siendo válida durante un determinado periodo de tiempo. La denominada «nulidad diferida» ha sido empleada recientemente en dos supuestos de infracción de la disposición adicional 3. a de la Constitución de 1978, sobre el régimen especial canario, lo que ha permitido que se ampliase su aplicación a otros casos de omisión, durante el procedimiento legislativo estatal, de informes autonómicos preceptivos.

PALABRAS Clave: nulidad diferida, leyes, declaración de inconstitucionalidad, comunidades autónomas, informes preceptivos.

\section{LAW'S DEFERRED NULLITY IN CASE OF OMISSION OF MANDATORY AUTONOMIC REPORTS}

\section{Abstract}

In the Spanish legal system, nullity is related to the idea of radical and retroactive disability. However, especially in recent years, the Constitutional Court has been making use of the possibility of delaying the effectiveness of a declaration of unconstitutionality, so that a null law remains valid for a certain period of time. The so-called "deferred nullity" has recently been used in two cases of infringement of the $3^{\text {rd }}$ additional provision of 1978 Constitution, about the Canary Islands special regime, which has allowed its application to be extended to other affairs of omission, during the procedure state legislature, of mandatory autonomic reports.

KEYwORDs: deferred nullity, laws, unconstitutionality declaration, autonomic communities, mandatory reports. 


\section{NOCIONES GENERALES SOBRE LA NULIDAD DIFERIDA}

La nulidad diferida se produce cuando se declara por parte del órgano competente la invalidez radical de un acto determinado, pero al mismo se pospone en el tiempo la plena eficacia de la indicada declaración. Por ello, el acto nulo sigue produciendo todos sus efectos hasta que se agota el plazo de diferimiento, durante el cual normalmente se habrá sustituido el susodicho acto nulo por otro nuevo y válido․

En una reciente Sentencia de 29 de marzo de 2017 (recurso contencioso-administrativo núm. 47/2014) ${ }^{2}$, la Sección 5. ${ }^{a}$ de la Sala Tercera del Tribunal Supremo ha reconocido que «desde la perspectiva de nuestro derecho interno una solución de esta naturaleza puede resultar extravagante, dado que en nuestro ordenamiento jurídico el concepto de nulidad de pleno derecho [...] se ha vinculado a la idea de invalidez radical ex tunc» (FJ 13..$^{\circ}$. Es decir: la carencia de efectos que se predica de cualquier acto nulo tiene alcance retroactivo. Lo ha recordado, en otra decisión reciente, la propia Sección 5. ${ }^{a}$ de la Sala Tercera: «La nulidad radical-explica el Alto Tribunal

${ }^{1}$ Díaz Revorio, F.J., «Tipología y efectos de las sentencias del Tribunal Constitucional en los procedimientos de inconstitucionalidad ante la reforma de la Ley Orgánica del Tribunal Constitucional español», en Ferrer Mac-Gregor Poisot, E. y Zaldívar Lelo de Larrea, A. (coordinadores), La ciencia del derecho procesal constitucional. Estudios en homenaje a Héctor Fix-Zamudio en sus cincuenta años como investigador del derecho, UNAM. IMDPC. Marcial Pons, México, 2008, tomo v, pp. 291-319. Según este autor, «en ciertas hipótesis de inconstitucionalidad sin nulidad, y particularmente cuando la falta de declaración de nulidad obedece a la finalidad de evitar vacíos legales, resulta necesaria una nueva intervención legislativa acorde con las previsiones constitucionales, que sustituya a los preceptos legales considerados inconstitucionales, y sin embargo mantenidos provisionalmente vigentes. En tales casos puede resultar conveniente no abandonar por completo la sanción de nulidad de la ley, sino tan solo retrasar ese efecto el tiempo suficiente para que el legislador proceda a aprobar una nueva regulación normativa. De ese modo, el tiempo de retraso en la aplicación de la nulidad es, en definitiva, el plazo del que dispone el legislador para la aprobación del nuevo precepto legal» (p. 311).

2 Con esta resolución, el Alto Tribunal resuelve el recurso contencioso-administrativo interpuesto por CEPSA contra el Acuerdo del Consejo de Ministros de 15 de noviembre de 2013, por el que se aprueba la asignación final gratuita de derechos de emisión de gases de efecto invernadero a las instalaciones sujetas al régimen de comercio de derechos de emisión para el periodo 2013-2020 y para cada año a cada instalación, publicado por Resolución de 23 de enero de 2014, de la Dirección General de la Oficina Española de Cambio Climático. La mercantil impugna, en concreto, las disposiciones relativas a una refinería de petróleo sita en San Roque (Cádiz). Ahora bien, las «partes personadas en el presente recurso manifestaron su conformidad con el hecho de que la resolución recurrida supone la aplicación al caso concreto y dentro del ámbito nacional de la Decisión 2013/448/ UE, aprobada el 5 de septiembre de 2013 por la Comisión, de forma tal que el debate procesal no se centra en analizar la corrección de la decisión del Consejo de Ministros por vicios o infracciones propias, sino que su enjuiciamiento está condicionado por la validez de la citada Decisión comunitaria de la que el Acuerdo ahora impugnado es una mera ejecución o traslación en el ámbito interno» (FJ 3..$^{\circ}$. Por ello, mediante Auto de 2 de julio de 2015, la Sala Tercera planteó ante el Tribunal de Justicia de la Unión Europea una cuestión prejudicial de validez contra la Decisión 2013/488/UE (FJ 6. ${ }^{\circ}$, que "fue resuelta mediante Auto de fecha 26 de octubre de 2016» (FJ 7. ${ }^{\circ}$. Así las cosas, la Sentencia de 29 de marzo de 2017 se centra en «resolver acerca de los efectos que tal decisión ha de tener sobre el procedimiento que nos ocupa» $\left(\mathrm{FJ} 10{ }^{\circ}\right)$. 
en una Sentencia de 2 de marzo de 2016 (recurso de casación núm. 1626/2015)³conlleva la pérdida de eficacia ex tunc (desde su origen), según el principio enunciado en los aforismos latinos quod nullum est, nullum producit efectum y quod ab initio vitiosum est, non potest tractu tempore convalescere» (FJ 7..$^{\circ}{ }^{4}$.

Ahora bien, volviendo a la Sentencia de 29 de marzo de 2017, «es lo cierto -prosigue la Sala Tercera- que la suspensión de los efectos de una declaración de invalidez de un acto o normativa [...] no resulta inusual en el ámbito de la justicia comunitaria. Si bien, con carácter general, el Tribunal de Justicia ha determinado que la interpretación de una norma comunitaria y su declaración de invalidez, pronunciadas en vía prejudicial, despliegan en principio efectos ex tunc, a contar desde el momento de su entrada en vigor [...], ello no es óbice para que, a título de excepción, atendiendo a consideraciones de seguridad jurídica, puedan tener efectos prospectivos» (FJ 13..$^{\circ}$. De hecho, en esta misma Sentencia que estamos comentando, la Sala Tercera tiene que hacer frente a las complejas consecuencias de un pronunciamiento de nulidad del Tribunal de Justicia de la Unión Europea cuyos efectos se limitan temporalmente «de modo que, por una parte, dicha declaración únicamente surta efectos tras un plazo de diez meses a partir de la fecha en que se dictó la Sentencia [...], con objeto de permitir que la Comisión adopte las medidas necesarias, $y$, por otra parte, no puedan impugnarse las medidas que hasta que termine dicho plazo se hayan adoptado de conformidad con las disposiciones anuladas» (FJ 8. ${ }^{\circ}$ ). Este tipo de decisiones se fundamentan en el segundo párrafo del art. 264 del Tratado de Funcionamiento de la Unión Europea, de acuerdo con el cual «el Tribunal indicará, si lo estima necesario, aquellos efectos del acto declarado nulo que deban ser considerados como definitivos" 5 .

${ }^{3}$ Dictada en el trámite de ejecución de la declaración de nulidad del Plan General de Ordenación Urbana de Valladolid en los ámbitos de la Fábrica de Piensos CIA y de la Azucarera Santa Victoria.

${ }^{4}$ En cambio, «el artículo L600-9 del Código Urbanístico francés permite al juez administrativo que conoce un recurso interpuesto contra un plan urbanístico, cuando el motivo alegado consiste en un vicio de procedimiento, suspender el procedimiento judicial y fijar un plazo en el que la Administración puede subsanar ese defecto. Durante ese período, el Plan recurrido sigue en vigor. Subsanado por la Administración el defecto de procedimiento, el juez resuelve el recurso». RenaU Faubell, F., «La nulidad "radioactiva” de los planes urbanísticos por defectos en el procedimiento de aprobación", Noticias Jurídicas, 10 de marzo de 2016, http://noticias.juridicas.com/conocimiento/ articulos-doctrinales/10946-la-nulidad-ldquo;radioactivardquo;-de-los-planes-urbanisticos-por-defectos-en-el-procedimiento-de-aprobacion/ (consultado el 6 de febrero de 2018).

5 Mangas Martín, A. y Liñán Nogueras, D.J., Instituciones y Derecho de la Unión Europea, 6. ${ }^{a}$ edición, Tecnos, Madrid, 2010, pp. 452-453. Como regla general, a la luz del primer párrafo del mismo art. 264 del Tratado de Funcionamiento, «la sentencia que declara nulo un acto posee una autoridad absoluta, desplegando los efectos de cosa juzgada material y formal. Además, la nulidad del acto produce, salvo la excepción que se mencionará, efectos ex tunc, [...] ya que se considera que el acto no ha existido y que los efectos jurídicos que haya desplegado deben ser eliminados». Pero, como hemos apuntado, el aludido segundo párrafo del art. 264 del Tratado «ha permitido al Tribunal de Justicia de la Unión Europea modular el efecto retroactivo de las sentencias de anulación en los supuestos de reglamentos y, también de otro tipo de actos declarados nulos», como «el acto de aprobación del presupuesto de la Unión adoptado por el Parlamento Europeo»; «en otros casos, el 
Pero es que «incluso nuestro Tribunal Constitucional -seguimos leyendo en la Sentencia de 29 de marzo de 2017 (FJ 14. ${ }^{\circ}$ ) - ha hecho uso de tal técnica», como ocurrió con la STC 13/2015, de 5 de febrero, que comentaremos más adelante. Al igual que la propia Sala Tercera, en realidad, que en su Sentencia de 22 de abril de 2014 (recurso contencioso-administrativo núm. 73/2013), tras declarar la nulidad "por vicios en su procedimiento de elaboración» del Real Decreto 1422/2012, de 5 de octubre, por el que se establecen las servidumbres aeronáuticas del aeropuerto de Lleida-Alguaire ${ }^{6}$, acordó «mantener, excepcional y provisionalmente, la eficacia de las servidumbres aeronáuticas establecidas [...], en tanto en cuanto no se apruebe un nuevo Real Decreto que sustituya al ahora anulado» ${ }^{7}$. El Tribunal justifica esta «limitación temporal -y excepcional- de la eficacia de nuestra Sentencia» por «razones imperiosas ligadas precisamente a la seguridad de la navegación aérea. En efecto, una vez comprobado que el régimen sustantivo de las servidumbres impuestas y de sus mecanismos de control (tanto para los actos como para los planes urbanísticos o de uso del suelo) es conforme a Derecho, la declaración de nulidad del Real Decreto 1422/2012 basada exclusivamente en motivos formales no puede tener como efecto inmediato que la navegación aérea con origen o destino en el aeropuerto de Lérida quede desprovista de las indispensables garantías de seguridad en atención a las cuales se prevén aquellas servidumbres (y su régimen de control preventivo). Aun cuando los arts. 71 y 72 de la Ley Jurisdiccional no contemplan de modo expreso la limitación de los efectos de las sentencias que acojan pretensiones de nulidad de los actos administrativos, la Sala estima que ante circunstancias excepcionales, y por razones muy cualificadas que atañen a la seguridad y a la vida de las personas, nada obsta a que se mantenga temporalmente la eficacia del acto anulado, en tanto es subsanado el defecto formal determinante de la nulidad de aquellos actos» (FJ 7.॰). La verdad, empero, es que a día de hoy el Real Decreto 1422/2012, de 5 de octubre, sigue en vigor sin cambios.

Tribunal ha admitido el mantenimiento de los efectos de una directiva declarada nula hasta la adopción de una nueva directiva que la sustituye».

${ }^{6}$ Según lo razonado por la Sala, «en la tramitación del Real Decreto 1422/2002 se ha omitido un trámite esencial, el de la audiencia de las administraciones locales y autonómica directa e inmediatamente interesadas y afectadas por unas medidas (la imposición de servidumbres sobre sus territorios) que limitan [...] el ejercicio de sus propias competencias, tanto las correspondientes al planeamiento urbanístico como a la ejecución de obras, actividades e instalaciones en sus respectivos territorios. La omisión de aquel trámite vicia de nulidad, desde el punto de vista formal, al Real Decreto mismo que ha dejado indefensas, en la fase previa a su aprobación, [tanto] a las corporaciones locales como el Ayuntamiento de Peralta de Calasanz» (FJ 2..$^{\circ}$.

7 BOE núm. 117, de 14 de mayo de 2014, p. 37716. 


\section{LA NULIDAD DIFERIDA EN LA PRÁCTICA DEL TRIBUNAL CONSTITUCIONAL}

Así las cosas, la nulidad diferida es una solución totalmente excepcional que queda reservada para supuestos en los que -como ha explicado, a propósito de la jurisprudencia del Tribunal Constitucional, la magistrada Encarnación Roca Trías en su voto particular a la STC 151/2017, de 21 de diciembre- «se trata de preservar bienes o valores que el Tribunal considera constitucionalmente relevantes y que justifican la desvinculación entre inconstitucionalidad y nulidad, siquiera durante un determinado período de tiempo». En la aludida STC 151/2017, por ejemplo, el Alto Tribunal difiere "hasta la convocatoria de un nuevo proceso de elecciones locales» la nulidad del párrafo tercero del art. 197.1 a) de la Ley Orgánica 5/1985, de 19 de junio, de régimen electoral general, en la redacción dada por la Ley Orgánica $2 / 2011$, de 28 de enero, con el fin de evitar «alteraciones en procedimientos de exigencia de responsabilidad política en curso por la ausencia de un régimen jurídico alternativo y respetuoso con la Constitución que cohoneste el principio de igualdad en el ejercicio de las funciones representativas y la prevención de los efectos perversos causados por el transfuguismo en los legítimos fines declarados por la norma» $\left(\mathrm{FJ} \mathrm{8.} .^{\circ}{ }^{8}\right.$. Y en la STC 195/1998, de 1 de octubre, para citar otro caso bien distinto, el mismo Tribunal dispuso que «la declaración de inconstitucionalidad de la Ley 6/1992, de 27 de marzo, por la que se declara Reserva Natural a las Marismas de Santońa y Noja no debe llevar aparejada la inmediata declaración de nulidad» para evitar «una desprotección medioambiental de la zona con graves perjuicios y perturbaciones a los intereses generales en juego y con afectación de situaciones y actuaciones jurídicas consolidadas» (FJ 5.०.).

${ }^{8}$ El voto particular de la vicepresidenta Encarnación Roca Trías se dirige justamente a denunciar la «imprudencia» cometida por el Tribunal Constitucional al «hacer un uso de la nulidad diferida que estimo inadecuado. De acuerdo con la finalidad a la que antes he hecho referencia, esta técnica sirve para preservar determinados valores o bienes a fin de evitarles la afectación que supone la declaración de inconstitucionalidad y nulidad de la norma que les da cobertura. Por eso, su aplicación exige determinar con claridad el bien cuya preservación reviste tanta entidad como para romper con la consecuencia lógica de la inconstitucionalidad de una norma, su nulidad y consiguiente expulsión del ordenamiento. En el presente caso, no alcanzo a comprender, ni la Sentencia lo explica, cuáles son los derechos, intereses, bienes o valores que tienen una relevancia constitucional tal que llevan a modular los efectos de nulidad propios de una sentencia de inconstitucionalidad. No cualquier valor o interés justifica el aplazamiento de la eficacia de la nulidad del precepto legal declarado inconstitucional. Por lo tanto, no ha quedado aquí acreditado que haya tal incidencia que justifique el mantenimiento de la vigencia de una norma inconstitucional durante casi ańo y medio». Más adelante agrega: "Creo que no se ha tenido en cuenta que esta Sentencia de nulidad diferida se ha dictado al resolver una cuestión de inconstitucionalidad, con lo que el órgano judicial va a verse obligado, en principio, a aplicar la norma declarada inconstitucional y que todavía no es nula». El magistrado Andrés Ollero Tassara discrepa, en su voto particular, en esta misma dirección: «La obvia inconstitucionalidad de la medida -afirma- ha de acarrear su nulidad e inmediata expulsión del ordenamiento jurídico». 
Esta necesidad de justificación casuística se debe a que -como se afirmara en la STC 45/1989, de 20 de febrero-, como norma general y «de acuerdo con lo dispuesto en la Ley Orgánica de este Tribunal (art. 39. 1), las disposiciones consideradas inconstitucionales han de ser declaradas nulas, declaración que tiene efectos generales a partir de su publicación en el Boletín Oficial del Estado (art. 38.1 de la LOTC) y que en cuanto comporta la inmediata y definitiva expulsión del ordenamiento de los preceptos afectados (STC 19/1987, FJ 6.') impide la aplicación de los mismos desde el momento antes indicado, pues la Ley Orgánica no faculta a este Tribunal, a diferencia de lo que en algún otro sistema ocurre, para aplazar o diferir el momento de efectividad de la nulidad» (FJ 11..$\left.^{\circ}\right)^{9}$. Ciertamente, según la mejor doctrina, «la previsión constitucional o legal expresa de este retraso da cobertura jurídica a una medida que, en otro caso, resultaría difícilmente justificable» ${ }^{10}$.

Precisamente por ello, durante la VIII Legislatura, se planteó la posibilidad de modificar el art. 39.1 de la Ley Orgánica 2/1979, de 3 de octubre, del Tribunal Constitucional con el siguiente contenido: «Cuando la sentencia declare la inconstitucionalidad, declarará igualmente la nulidad de los preceptos impugnados o cuestionados. No obstante, motivadamente y para preservar los valores e intereses que la Constitución tutela, la sentencia podrá declarar únicamente la inconstitucionalidad o diferir los efectos de la nulidad por un plazo que en ningún caso será superior a tres años $\aleph^{11}$. Este Proyecto de Ley Orgánica ${ }^{12}$, presentado por el Gobierno a finales de 2005, definía la regla que queda transcrita como un «aspecto novedoso" que "habilita al Tribunal Constitucional para conceder un plazo extraordinario de suspensión de la eficacia de la nulidad de los preceptos inconstitucionales a la espera de su sustitución por el legislador", pero sólo en el caso -como decíamos- de que «expresamente se justifique la concurrencia de algún interés constitucional que resulte protegido por la adopción de este efecto extraordinario». Pese a tales prevenciones, este "aspecto novedoso» fue rechazado en hasta tres enmiendas presentadas en el Congreso:

9 El ordenamiento constitucional de la República de Austria, por ejemplo, contempla expresamente el retraso de la "eficacia derogatoria» de sus sentencias, como han explicado en nuestra doctrina Gómez Corona, E., «El control de constitucionalidad de la ley en España. Análisis de la jurisprudencia constitucional (1980-2008)», Revista de Derecho Político, núm. 74, enero-abril 2009, pp. 263-288, (pp. 278-279, nota 30); y Díaz Revorio, op. cit., p. 311, según el cual en dicho país «la posibilidad de retrasar los efectos de la anulación de la ley tiene amparo constitucional expreso, pudiendo el tribunal constitucional disponer dicho retraso en los efectos de la sentencia de inconstitucionalidad, hasta un máximo de dieciocho meses».

${ }^{10}$ Díaz Revorio, op. cit., pp. 311-312.

${ }^{11}$ El tenor original -y aún vigente- de dicho precepto es como sigue: «Cuando la sentencia declare la inconstitucionalidad, declarará igualmente la nulidad de los preceptos impugnados, así como, en su caso, la de aquellos otros de la misma Ley, disposición o acto con fuerza de Ley a los que deba extenderse por conexión o consecuencia».

12 «Proyecto de Ley Orgánica por la que se modifica la Ley Orgánica 2/1979, de 3 de octubre, del Tribunal Constitucional». Boletín Oficial de las Cortes Generales, serie A, 25 de noviembre de 2005, núm. 60-1. Véanse especialmente las pp. 2 y 6. 
I. El Grupo Parlamentario Vasco (EAJ-PNV) arguyó que la nueva potestad del Alto Tribunal se funda en un "difuso criterio» y que «abre un panorama para los aplicadores de las normas, en primer término, y para la ciudadanía, en términos generales, confuso y vulnerable, toda vez que en el lapso de tiempo dilatado que se le otorga al legislador para reponer la ley declarada inconstitucional, los jueces y tribunales deberán aplicar una ley que no ha sido anulada o enfrentarse a una posible cuestión de inconstitucionalidad por inaplicar una ley que, si bien deviene inconstitucional, sigue vigente hasta su sustitución. Ello, sin entrar en otros supuestos en los que puedan afectarse derechos fundamentales. El legislador debe ejecutar las sentencias en el menor tiempo posible y no cabe que se le exima o atenúe tal obligación mediante privilegios que resultan totalmente contrarios a la seguridad jurídica. Lo que ha venido siendo excepcional -y altamente criticado- hasta la fecha, quiere pasar a ser "normal" si contemplamos que en los escasos supuestos en que se ha diferido la nulidad a la sustitución de la norma el legislador ha tardado más de lo habitual en cualquier proceso legislativo en aprobar la correspondiente norma ${ }^{13}$.

II. El Grupo Parlamentario Popular en el Congreso argumentó que la potestad que comentamos no era procedente "por coherencia con la posición constitucional que corresponde a las Cortes Generales. El Tribunal Constitucional no puede sustituir al legislador: facultarle para suplir lagunas normativas es atribuirle facultades legislativas, lo que es inconstitucional». Además, también apuntó que «el plazo de inconstitucionalidad con nulidad diferida es demasiado amplio, generando una enorme inseguridad jurídica» ${ }^{14}$.

III. El Grupo Parlamentario Catalán (Convergència i Unió) rehusó la inconstitucionalidad sin nulidad, en la medida en que «la introducción de que la declaración de inconstitucionalidad de una norma quede independizada de su nulidad, de forma absoluta y permanente, no encuentra apoyo en el art. 161 de la Constitución», pero no la nulidad diferida, que mantuvo en los términos propuestos por el Gobierno en su Proyecto ${ }^{15}$.

Finalmente, la modificación del art. 39 de la LOTC no fue incluida en el Informe de la Ponencia ${ }^{16}$, por lo que quedó fuera de la reforma que venimos comentando ${ }^{17}$. Y ello a pesar de que algunos autores se habían mostrado verdaderamente

13 Boletín Oficial de las Cortes Generales, serie A, 23 de febrero de 2006, núm. 60-7, pp. 31-32, enmienda núm. 24.

14 Ibidem., p. 45, enmienda núm. 57.

${ }^{15}$ Ibidem., p. 57, enmienda núm. 95.

16 Boletín Oficial de las Cortes Generales, serie A, 5 de diciembre de 2006, núm. 60-9.

17 Gómez Corona, op. cit., pp. 278-279 y nota 31. 
esperanzados ante este cambio legislativo ${ }^{18}$, al considerar que era necesario -en palabras del profesor Díaz Revorio- para resolver el «acuciante» problema de «la falta de cobertura legal expresa [...], o incluso, para ser más claros, de la prohibición legal expresa de toda medida que desvincule inconstitucionalidad y nulidad [...]. En este sentido, y teniendo en cuenta que en determinadas ocasiones este tipo de medidas puede presentarse como la opción "menos mala" en el sentido de menos alejada de la Constitución y más respetuosa con las competencias y funciones de otros poderes del Estado, la doctrina venía reclamando insistentemente la reforma de la LOTC para contemplar y permitir el uso de estos fallos en las sentencias sobre la constitucionalidad de la ley» ${ }^{19}$.

La verdad, empero, es que, en un análisis estadístico de 356 pronunciamientos de inconstitucionalidad efectuados por el Tribunal Constitucional desde sus orígenes hasta 2008, la profesora Esperanza Gómez Corona ha contabilizado tan sólo un total de siete fallos estimatorios con declaración de nulidad diferida ${ }^{20}$. Con posterioridad se han producido algunos más, como ya hemos visto, entre los cuales destacamos primeramente la STC 164/2013, de 26 de septiembre: el primer asunto en el que el Alto Tribunal difiere la nulidad de una ley tras declararla inconstitucional por haberse omitido durante su elaboración un informe autonómico de carácter preceptivo ${ }^{21}$.

18 Gómez Corona, op. cit., p. 279, aludiendo a la mentada STC 195/1998, incluso afirma que «no cabe sino felicitarse del atrevimiento del Tribunal Constitucional a la hora de actuar al margen de la propia LOTC, pues este quebrantamiento se compensa por la protección que se dispensa a estas zonas si se compara con el efecto que tendría la anulación de la normativa estatal sin más, aunque ello se hiciera con escrupuloso cumplimiento de lo establecido en la LOTC».

19 Díaz Revorio, op. cit., p. 308 y nota 15 . Ahora bien, según este mismo autor, «el plazo que la ley establece como máximo resulta un tanto excesivo, tanto desde la perspectiva del derecho comparado (el plazo máximo existente en Austria es la mitad), como si se tiene en cuenta la necesidad de no demorar, más allá del tiempo estrictamente imprescindible, la exigencia al legislador del cumplimiento de los mandatos constitucionales. Por ello creo que puede afirmarse que prácticamente cualquier modificación legislativa imaginable puede llevarse a cabo (mucho más cuando existen poderosas exigencias constitucionales para hacerlo) en un período bastante inferior a tres años» (p. 312).

${ }^{20}$ Gómez Corona, op. cit., pp. 266 y 270.

21 Requejo Pagés, J.L., Duque Villanueva, J.C., Ortega Carballo, C. y Ahumada Ruiz, M., "Doctrina del Tribunal Constitucional durante el tercer cuatrimestre de 2013", Revista Española de Derecho Constitucional, núm. 100, enero-abril de 2014, pp. 267-312, (pp. 288-289). Estos autores destacan que es poco "habitual» que "el Tribunal recurra a la "nulidad diferida"», lo que convierte la STC 164/2013 en un pronunciamiento «singular no sólo por las razones aducidas para justificar la excepción a la regla de la declaración de inconstitucionalidad y nulidad que fija el art. 39.1 LOTC, sino, sobre todo, porque por primera vez el Tribunal fija un plazo determinado (un ańo) para que comience a desplegar sus efectos la declaración de nulidad». 
Con la STC 164/2013, en concreto, el Tribunal declara la inconstitucionalidad de las normas impugnadas por el Parlamento de Canarias en el recurso núm. 2703-2011 -a saber: la disposición transitoria $8 .^{a}$ y las disposiciones finales $27 .{ }^{a}, 28 .^{a}$ y $30 .^{a}$ de la Ley $2 / 2011$, de 4 de marzo, de economía sostenible- al constatar «la omisión de toda audiencia previa a la Comunidad Autónoma de Canarias» (FJ 6. ${ }^{\circ}$ ).

La disposición adicional $3{ }^{a}$ de la Constitución española de 27 de diciembre de 1978, en efecto, establece que «la modificación del régimen económico y fiscal del archipiélago canario requerirá informe previo de la Comunidad Autónoma o, en su caso, del órgano provisional autonómico». El art. 46 del Estatuto de Autonomía de Canarias (Ley Orgánica 10/1982, de 10 de agosto) desarrolla este precepto constitucional al señalar, de entrada, que el régimen económico-fiscal especial de Canarias es "propio de su acervo histórico y constitucionalmente reconocido, basado en la libertad comercial de importación y exportación, no aplicación de monopolios y en franquicias aduaneras y fiscales sobre el consumo» (apartado 1). Este régimen - contempla a su vez el apartado 3 del mismo art. 46- «sólo podrá ser modificado de acuerdo con lo establecido en la disposición adicional $3 .{ }^{a}$ de la Constitución, previo informe del Parlamento Canario que, para ser favorable, deberá ser aprobado por las dos terceras partes de sus miembros». El art. 46.4 del mismo Estatuto aún agrega que «el Parlamento Canario deberá ser oído en los proyectos de legislación financiera y tributaria que afecten al régimen económico-fiscal de Canarias».

En el FJ $4^{\circ}$ de esta misma STC 164/2013, de 26 de septiembre, el Tribunal Constitucional ha tenido oportunidad de sintetizar su «cuerpo doctrinal consolidado» sobre la "garantía procedimental» que para el régimen especial canario establece la disposición adicional $3 .^{2}$ de la Carta Magna ${ }^{22}$ :

I. «Este informe [del Parlamento Canario] es exigible siempre que la norma estatal [...] suponga una modificación de los elementos que integran el régimen económico-fiscal de Canarias".

II. «Para que pueda entenderse que una norma está destinada a modificar el régimen económico y fiscal, resultando exigible el citado informe previo, hemos afirmado que basta con que se modifiquen algunos de los elementos que lo integran».

22 Elvira Perales y Gómez Lugo (coordinadores), Pajares Montolío, Fraile Ortiz y Espinosa Díaz, «Actividad del Tribunal Constitucional: relación de sentencias dictadas durante el tercer cuatrimestre de 2013", Revista Española de Derecho Constitucional, núm. 100, enero-abril de 2004, pp. 245-266, (p. 246). En este análisis se destaca la recapitulación de la «doctrina sobre el régimen económico y fiscal canario en el contexto de la DA 3. ${ }^{a}$ CE, ya desde la STC 35/1984: nulidad de los preceptos legales que afectan al régimen especial canario y que fueron aprobados sin respetar el trámite de audiencia previa a la Comunidad Autónoma previsto en su Estatuto de Autonomía». 
III. El informe en cuestión «no es vinculante, de manera que su sentido desfavorable no impide la modificación del régimen especial canario [...]; pero sí es preceptivo, por lo que su ausencia determina la inconstitucionalidad de la norma pertinente». Así ocurrió por vez primera, recuerda el Tribunal, con la STC 35/1984, de 13 de marzo, que declaró la inconstitucionalidad del Real Decreto-ley 1/1983, de 9 de febrero, por el que se deroga la exacción sobre el precio de las gasolinas de automoción «en todo lo que se refiere a las islas Canarias, normativa que en tal sentido se anula».

IV. «La misma consecuencia de inconstitucionalidad de la norma tiene la omisión de la "audiencia" a que se refiere el art. 46.4 del Estatuto de Autonomía de Canarias [...]. Ambos (informe y audiencia) son constitucionalmente exigibles cuando se dan los presupuestos de hecho contenidos en la norma».

v. «El momento idóneo para solicitarlo era antes de la tramitación de la iniciativa legislativa en las Cortes Generales, "justamente para que en ésta pueda tomarse en consideración el parecer del Parlamento canario". Ahora bien, ello no impide su solicitud en un momento posterior, que resulta además exigible, debiéndose incluso solicitar un nuevo informe cuando en dicho debate se introduzcan modificaciones que alteren el proyecto "tan radicalmente que no pueda tenerse por informado"».

En definitiva, «toda afectación o modificación del régimen [especial canario] [...] requieren para su aprobación bien de audiencia, bien que se solicite informe previo del Parlamento canario, informe y audiencia previa que no resultan vinculantes pero sí son preceptivos, de manera que la ausencia de su solicitud determina la inconstitucionalidad de la norma que modifique o afecte al régimen económico y fiscal canario».

La gran novedad de la STC 164/2013 estriba, como decíamos, en los «términos» de esta declaración de inconstitucionalidad, que quedan expresados en su FJ 7.․ Así, el Tribunal considera que "la nulidad inmediata que, como regla y de acuerdo con el art. 39.1 de la LOTC, sigue a un pronunciamiento de inconstitucionalidad, debe ser matizada en este caso concreto" por los siguientes motivos:

I. «Las disposiciones finales 27. ${ }^{\text {y }} 28$. $^{a}$ [de la Ley $2 / 2011$, de 4 de marzo, de economía sostenible] se aprobaron para reflejar las modificaciones a la Ley 37/1992, de 28 de diciembre, del impuesto sobre el valor añadido consecuencia de su adaptación al Derecho de la Unión Europea, por lo que no cabe descartar que su nulidad pudiera suponer también una infracción del mismo».

II. «La reserva para inversiones en Canarias, a que se refieren la disposición transitoria $8{ }^{a}$ y la final $30 .^{a}$, ha sido modificada precisamente para incentivar la realización de determinadas inversiones en esta Comunidad Autónoma, de acuerdo con la finalidad de su régimen especial, por lo que la anulación inmediata del precepto generaría previsiblemente un perjuicio directo a esta misma Comunidad».

Así las cosas, prosigue el Tribunal, «para cohonestar por un lado la exigencia procedimental del informe previo de la Comunidad Autónoma de Canarias, que 
viene establecida directamente por la Constitución, y, por otro, los propios intereses de la Comunidad Autónoma de Canarias, que podrían experimentar un perjuicio derivado de vacíos normativos, la nulidad derivada de la declaración de inconstitucionalidad debe quedar diferida por el plazo de un año, plazo que se considera razonable para que, en su caso, se sustituyan las normas declaradas nulas una vez observado el procedimiento constitucional del informe previo emitido por el poder legislativo de la Comunidad Autónoma de Canarias».

El Tribunal Constitucional recuperó esta modulación un año después, en la STC 164/2014, de 7 de octubre ${ }^{23}$, al resolver un nuevo recurso de inconstitucionalidad formulado por el Parlamento de Canarias: en esta ocasión, contra la disposición adicional 13. ${ }^{a}$ de la Ley 17/2012, de 27 de diciembre, de presupuestos generales del Estado para 2013, intitulada «subvenciones al transporte marítimo y aéreo para residentes en Canarias, Baleares, Ceuta y Melilla». Esta norma es nuevamente declarada inconstitucional y nula por infringir la "garantía procedimental» que regulan la disposición adicional $3 .^{\text {a }}$ de la Constitución y el art. 46 del Estatuto de Autonomía de Canarias, pero el Alto Tribunal decide "diferir los efectos de la nulidad, como también hicimos en la STC 164/2013" (FJ 3..$^{\circ}$. "Así», leemos en el pasaje final de la STC 164/2014, «debe establecerse una excepción a la nulidad inmediata que, como regla y de acuerdo con el art. 39.1 de la Ley Orgánica del Tribunal Constitucional, sigue a un pronunciamiento de inconstitucionalidad, para atender adecuadamente a otros valores con trascendencia constitucional como los derechos de los destinatarios de las subvenciones que se verían directamente perjudicados si la norma fuera declarada nula de forma inmediata. Por tanto, para cohonestar por un lado la exigencia procedimental del informe previo de la Comunidad Autónoma de Canarias, que viene establecida directamente por la Constitución, y, por otro, los intereses de los destinatarios de la norma, que podrían experimentar un perjuicio derivado de vacíos normativos, la nulidad derivada de la declaración de inconstitucionalidad debe quedar diferida por el plazo de un ańo a partir de la publicación de esta sentencia ${ }^{24}$, periodo de tiempo en el que se deberá proceder a sustituir las normas declaradas nulas una vez observado el procedimiento constitucional del informe previo emitido por el poder legislativo de la Comunidad Autónoma de Canarias» $\left(\mathrm{FJ} 3 .^{\circ}\right)^{25}$.

23 Requejo Pagés, J.L., Duque Villanueva, J.C., Ortega Carballo, C. y Ahumada Ruiz, M., «Doctrina del Tribunal Constitucional durante el tercer cuatrimestre de 2014», Revista Española de Derecho Constitucional, núm. 103, enero-abril de 2015, pp. 259-304, (pp. 276-277, 281, 285). La profesora Ahumada Ruiz señala como «la STC 164/2014 [...] siguiendo la pauta de la STC $164 / 2013$, reitera la novedosa práctica de diferir el efecto de la nulidad fijando al tiempo un plazo de un año para que se proceda a la sustitución de la norma declarada inconstitucional (por haber incurrido en un vicio de procedimiento determinante de la inconstitucionalidad)» (p. 285).

24 BOE núm. 262, de 29 de octubre de 2014.

25 En este asunto, además, el Tribunal también tuvo que precisar que «dado que la norma impugnada se refiere, de forma conjunta, a las subvenciones al transporte "para residentes en Canarias, Baleares, Ceuta y Melilla”, la citada declaración de inconstitucionalidad y nulidad debe limitarse a lo que de esta norma se refiere a los residentes en Canarias» (FJ 3..$^{\circ}$. 
Mientras que los preceptos de la Ley 2/2011, de 4 de marzo, de economía sostenible declarados nulos (diferidamente) por la STC 164/2013 nunca fueron «sustituidos", por lo que hoy -transcurrido con creces el plazo de un año concedido al efecto por el Tribunal- deben considerarse ineficaces, la disposición adicional $13{ }^{a}$ de la Ley 17/2012 sí fue «sustituida» del modo señalado por la STC 164/2014. En junio de 2015, el Ministerio de Fomento remitió al Parlamento de Canarias un «Proyecto de modificación de la disposición adicional décima tercera de la Ley 17/2012, de 27 de diciembre, de Presupuestos Generales del Estado para el año 2013, por la que se regulan las subvenciones al transporte, marítimo y aéreo, regular de pasajeros en lo que afecta a los residentes en Canarias». En su reunión del 14 de julio, la Mesa del Parlamento adoptó los acuerdos oportunos para proceder a la tramitación requerida "para dar cumplimiento a la Sentencia del Tribunal Constitucional 164/2014, de 7 de octubre, de acuerdo con lo establecido en el art. 46.3 del Estatuto de Autonomía ${ }^{26}$. Finalmente, el Pleno de la Cámara, en su reunión del 21 de julio de 2015, emitió «informe desfavorable» ${ }^{27}$. Lo cual no fue óbice para que la disposición final $10 .^{a}$ de la Ley 40/2015, de 1 de octubre, de Régimen Jurídico del Sector Público modificase en el sentido propuesto por el Gobierno la disposición adicional $13{ }^{a}$ de la Ley $17 / 2012$, porque -como ya hemos visto- «el informe exigido en la Constitución y la norma estatutaria, si bien es preceptivo, no es vinculante» [STC 164/2014, FJ 2. ${ }^{\circ}$, apartado b)].

\subsection{Los asuntos relativos al art. 72.3 del Estatuto de Autonomía de Aragón: LA STC 13/2015 y LA STC 155/2017}

La doctrina jurisprudencial sobre la disposición adicional $3 .^{\text {a }}$ de la Constitución que acabamos de exponer ha sido aplicada recientemente por el Tribunal Constitucional en un litigio relativo al art. 72.3 del Estatuto de Autonomía de Aragón (Ley Orgánica 5/2007, de 20 de abril), de acuerdo con el cual, «para la defensa de los derechos relacionados con el agua contemplados en el art. 19, la Comunidad Autónoma emitirá un informe preceptivo para cualquier propuesta de obra hidráulica o de transferencia de aguas que afecte a su territorio». El indicado art. 19 regula los «derechos en relación con el agua»: por un lado, la facultad de los aragoneses de «disponer del abastecimiento de agua en condiciones de cantidad y calidad suficientes para atender sus necesidades presentes y futuras, tanto para el consumo humano como para el desarrollo de actividades sociales y económicas que permitan la vertebración y el reequilibrio territorial de Aragón» (apartado 1); y, por el otro, la doble obligación de los "poderes públicos aragoneses» de velar por «la conservación y mejora de los recursos hidrológicos, ríos, humedales y ecosistemas y paisajes vinculados, mediante la promoción de un uso racional del agua, la fijación de cau-

26 Boletín Oficial del Parlamento de Canarias, núm. 11, de 17 de julio de 2015.

27 Ibidem, núm. 273, de 30 de agosto de 2016. 
dales ambientales apropiados y la adopción de sistemas de saneamiento y depuración de aguas adecuados» (apartado 2) y "para evitar transferencias de aguas de las cuencas hidrográficas de las que forma parte la Comunidad Autónoma que afecten a intereses de sostenibilidad, atendiendo a los derechos de las generaciones presentes y futuras» (apartado 3).

En su STC 110/2011, de 22 de junio, por cierto, el Tribunal Constitucional avaló expresamente el art. 72.3 del Estatuto de Autonomía de Aragón al considerar que «la emisión de informes preceptivos por parte de las Comunidades Autónomas en el seno de procedimientos estatales, o viceversa, ha sido considerada por la doctrina de este Tribunal [...] una técnica adecuada para los supuestos de concurrencia de competencias" (FJ 15. ${ }^{\circ}$ ). Se citan al respecto la STC 243/1993, de 15 de julio, y la STC 31/2010, de 28 de junio, entre otras (FJ 9. ${ }^{\circ}$ ).

Pues bien, las Cortes de Aragón promovieron en 2014 recurso de inconstitucionalidad contra la disposición adicional $15 .{ }^{a}$, la disposición transitoria $2^{\mathrm{a}}$, la disposición derogatoria única, apartado 3 , y las disposiciones finales $2 .{ }^{\mathrm{a}}, 3 .{ }^{\mathrm{a}}, 4{ }^{\mathrm{a}}{ }^{\mathrm{a}}$ y $5 .^{\mathrm{a}} \mathrm{de}$ la Ley 21/2013, de 9 de diciembre, de evaluación ambiental. En su STC 13/2015, de 5 de febrero $^{28}$, el Alto Tribunal declara la inconstitucionalidad de tales normas, por ser «contrarias» al art. 72.3 del antedicho Estatuto de Autonomía, al haberse omitido «el preceptivo trámite de audiencia a la Comunidad Autónoma de Aragón». Ahora bien, haciendo mención expresa de la STC 164/2013 y la STC 164/2014, «en ambos casos por referencia a la participación del Parlamento de Canarias», el Tribunal de nuevo modula los «términos» de la declaración de nulidad de un modo que ya conocemos:

La nulidad inmediata que, como regla y de acuerdo con el art. 39.1 de la LOTC, sigue a un pronunciamiento de inconstitucionalidad, debe ser matizada en este caso concreto ya que todas estas disposiciones se refieren al régimen de transferencias hídricas a través del acueducto Tajo-Segura, cuya trascendencia está fuera de toda duda de suerte que la anulación de las normas antes mencionadas es susceptible de generar graves perjuicios a los intereses generales. Por tanto, para cohonestar por un lado la exigencia procedimental del informe previo de la Comunidad Autónoma de Aragón, y, por otro, los propios intereses de las restantes Comunidades Autónomas afectadas por el trasvase y del resto de los destinatarios de la norma que podrían experimentar un perjuicio derivado de vacíos normativos, la nulidad

${ }^{28}$ Elvira Perales, Espinosa Díaz (coordinadores), Pajares Montolío, Fraile Ortiz, Gómez Lugo, «Actividad del Tribunal Constitucional: relación de sentencias dictadas durante el primer cuatrimestre de 2015", Revista Española de Derecho Constitucional, núm. 104, mayo-agosto de 2015, pp. 171-199, (p. 173); Requejo Pagés, J.L., Duque Villanueva, J.C., Ortega Carballo, C. y Ahumada Ruiz, M., "Doctrina del Tribunal Constitucional durante el primer cuatrimestre de 2015", Revista Española de Derecho Constitucional, núm. 104, mayo-agosto de 2015, pp. 201-242, (pp. 206 y 215); Blasco Hedo, E., "Jurisprudencia al día. Tribunal Constitucional. Aragón. Trasvase Tajo-Segura. Sentencia del Pleno del Tribunal Constitucional de 5 de febrero de 2015 (ponente: Luis Ignacio Ortega Álvarez)», Actualidad Jurídica Ambiental, 25 de marzo de 2015, disponible en <http://www.actualidadjuridicaambiental.com/jurisprudencia-al-dia-tribunal-constitucional-aragon-trasvase-tajo-segura/> (consultado el 13 de febrero de 2018). 
derivada de la declaración de inconstitucionalidad debe quedar diferida por el plazo de un año, a partir de la publicación de esta Sentencia, periodo de tiempo en el que se deberá proceder a sustituir las normas declaradas nulas una vez observado el procedimiento del informe previo emitido por la Comunidad Autónoma de Aragón [FJ 5. ${ }^{\circ}$, apartado e)].

En fechas más recientes, con su STC 155/2017, de 21 de diciembre ${ }^{29}$, el Alto Tribunal se ha pronunciado nuevamente sobre este mismo asunto, al resolver el recurso interpuesto por el Gobierno de la Comunidad Autónoma de Aragón contra la disposición adicional 5. a , la disposición transitoria única, la disposición derogatoria única y las disposiciones finales 1 . $^{a}$ y 2. ${ }^{a}$ de la Ley 21/2015, de 20 de julio, por la que se modifica la Ley 43/2003, de 21 de noviembre, de montes. Estas normas son «en todo idénticas a las declaradas inconstitucionales y nulas en la STC 13/2015 por haberse omitido, antes de su aprobación parlamentaria, el trámite de informe» (FJ 4..$^{\circ}$, como acabamos de explicar.

Así las cosas, la parte recurrente aduce en el caso resuelto por la STC 155/2017 una nueva infracción del art. 72.3 del Estatuto de Autonomía de Aragón, mas en esta ocasión, «a diferencia [...] de lo ocurrido en el procedimiento parlamentario enjuiciado en la STC 13/2015, la Cámara sí interesó [...] el informe de la Comunidad Autónoma, de modo que la discusión procesal se ha de entender objetivamente ceñida a si el informe se pidió de una manera regular y en términos tales que permitieran a aquélla manifestar con efectividad su criterio al respecto. Esto es lo que la demanda niega con el argumento de que el "escaso lapso de tiempo transcurrido hasta la aprobación de la ley" [...] desde que el repetido informe fuera interesado vino a impedir a la Comunidad Autónoma cumplir con este trámite» (FJ 4. ${ }^{\circ}$ ).

El Tribunal Constitucional afirma que «la actuación del Congreso de los Diputados merece, sin duda, algunos reproches» [FJ 7. , apartado a)], pero tal «cuestionable proceder, «matiza a continuación»,

no provoca, en sí mismo considerado, la inconstitucionalidad de las disposiciones de ley que en este recurso se pretende. La mencionada Cámara legislativa, a diferencia de lo planteado en el caso resuelto por la STC 13/2015, no omitió, sin más, la solicitud del informe autonómico, informe que fue efectivamente recabado. Por tanto, los preceptos impugnados sólo podrían llegar a considerarse incursos en invalidez si, atendida la tramitación desenvuelta en las Cortes Generales y las demás circunstancias relevantes, la atribución que establece el art. 72.3 del Estatuto de Autonomía de Aragón hubiera sido de imposible ejercicio o defensa por parte de las instituciones autonómicas, pues bien claro está que un vicio de procedimiento como el que aquí hemos constatado no habría de afectar finalmente a la ley, vicián-

29 Blasco Hedo, E., «Jurisprudencia al día. Tribunal Constitucional. Aragón. Trasvase Tajo-Segura. Sentencia 155/2017 del Pleno del Tribunal Constitucional, de 21 de diciembre de 2017 (Ponente: Fernando Valdés Dal-Ré)», Actualidad Juridica Ambiental, 13 de febrero de 2018, disponible en <http://www.actualidadjuridicaambiental.com/jurisprudencia-al-dia-tribunal-constitucional-aragon-trasvase-tajo-segura-2/> (consultado el 13 de febrero de 2018). 
dola a su vez, si la participación de la Comunidad Autónoma prevista en aquella disposición del Estatuto hubiera podido, pese a todo, ser ejercida o, cuando menos, invocada ante las Cámaras con alguna posible eficacia, de haberlo intentado así los correspondientes órganos de la Comunidad Autónoma» [FJ 7. ${ }^{\circ}$ apartado b) $]^{30}$.

Tras analizar las concretas circunstancias del caso, se concluye en la STC 155/2017, «el Tribunal no aprecia que, a lo largo de la tramitación en las Cortes Generales [...], la Comunidad Autónoma se hubiera visto privada, en todo momento y en términos absolutos, de la posibilidad de ejercer o, en su defecto, de hacer valer la atribución estatutaria (art. 72.3) que su Gobierno ahora invoca» (FJ 8..$^{31}$, de modo que procede la desestimación del recurso de inconstitucionalidad interpuesto ${ }^{32}$.

30 De hecho, la STC 155/2017 precisa que la «efectiva emisión» del informe autonómico no constituye "condición de intervención indispensable o necesaria para el perfeccionamiento de la ley. $\mathrm{Si}$, en efecto, el parecer autonómico hubiera sido oportuna y regularmente recabado y si la Comunidad Autónoma, en hipótesis, hubiera omitido la manifestación de su criterio en el plazo al efecto fijado, no por ello la prosecución del trámite legislativo sin ese informe determinaría que la ley finalmente aprobada hubiera nacido viciada, siendo inasumible la conclusión contraria, que supondría tanto como conferir a la Comunidad Autónoma un poder de veto ex silentio frente al ejercicio de la potestad legislativa del Estado sobre ámbitos de su exclusiva competencia. En definitiva, cuando corresponde a una u otra de las Cámaras, o a ambas, sucesivamente, interesar esta intervención autonómica, lo que está en juego con carácter prioritario es el debido respeto a la facultad de informar, mediante la necesaria solicitud al efecto. A resultas de tal respeto o transgresión sería de considerar la regularidad o irregularidad procedimental de la ley, de modo que solo cuando aquella necesaria solicitud no se hubiera realizado en absoluto [...] o cuando se hubiera llevado a cabo en términos tales que hicieran de todo punto imposible o ineficaz la intervención autonómica [...] cabría concluir en que habría resultado desconocida la atribución autonómica y viciada, por esta causa, la disposición de ley adoptada sin dar en absoluto ocasión a la Comunidad Autónoma de hacer llegar a las Cortes su criterio o, eventualmente, de defender y hacer valer, en curso aún el procedimiento legislativo, la propia atribución" [FJ 5. ${ }^{\circ}$, apartado b)].

${ }^{31}$ Los hechos enjuiciados en la STC 155/2017 son sintetizados del siguiente modo por el propio Tribunal: «La Comunidad Autónoma de Aragón fue requerida, aunque de modo y en circunstancias formalmente poco atentas, para emitir su informe. Y ni lo llegó a evacuar, pudiendo haberlo hecho ante el Senado, ni invocó tampoco ante las Cortes Generales, en curso todavía el procedimiento legislativo, el menoscabo de la atribución propia que hoy defiende, menoscabo que pudo acaso haberse reparado en aquel procedimiento y que no es dable aducir frente a la ley cuando, como aquí es de ver, no se intentó en modo alguno. Por consiguiente, no es razonable imputar a la actuación del Congreso de los Diputados un vicio de invalidez de las disposiciones de ley que se impugnan» (FJ 8..$^{\circ}$.

32 El magistrado Cándido Conde-Pumpido Tourón se opone a este fallo - y a su fundamentación- con un rotundo voto particular que concluye del modo siguiente: «Teniendo en cuenta el significado institucional de la previsión del informe (que, según la STC 13/2015, [...] "tiene por objeto establecer un mecanismo de cooperación en un ámbito en el que resultan afectados intereses estatales y autonómicos") y el rango de la norma que lo exige (norma institucional básica de una Comunidad Autónoma y, por tanto, perteneciente al bloque de la constitucionalidad), no puedo compartir la nula consideración que se refleja en la Sentencia hacia un mecanismo de cooperación del que tan necesitado está nuestro Estado autonómico para lograr la cooperación en el ejercicio de competencias, tanto del Estado como de las Comunidades Autónomas, que confluyen en el mismo espacio físico. El presente pronunciamiento desatiende tanto el principio de cooperación como el de lealtad institucional, principios que deben regir nuestro sistema autonómico para prevenir en lo posible 


\section{CONCLUSIONES}

a) Denominamos «nulidad diferida» aquel fenómeno jurídico que se produce cuando el órgano competente declara la invalidez radical de un acto determinado, pero al mismo pospone en el tiempo la plena eficacia de la indicada declaración. Es habitual el uso de este instrumento en la jurisprudencia del Tribunal de Justicia de la Unión Europea, en virtud del art. 264 del Tratado de Funcionamiento de la Unión, mientras que nuestro Tribunal Supremo todavía lo considera algo "extravagante».

b) El Tribunal Constitucional, pese a no contar con habilitación legal para ello, utiliza con cierta frecuencia este instituto, pero motivando siempre de modo preciso el valor o interés constitucional que pretende preservarse con su empleo y señalando, además, el plazo concreto de diferimiento. La doctrina ha considerado «conveniente» este expediente procesal ${ }^{33}$.

c) Un supuesto paradigmático de nulidad diferida en la jurisprudencia del Tribunal Constitucional suele darse cuando se declara la inconstitucionalidad de una ley por haberse incumplido un "trámite procedimental inexcusable» ${ }^{34}$ durante su elaboración: por ejemplo, la omisión de un informe autonómico preceptivo. En tales casos, como ha apreciado la misma doctrina, «el tiempo de retraso en la aplicación de la nulidad es, en definitiva, el plazo del que dispone el legislador para la aprobación del nuevo precepto legal $\aleph^{35}$.

d) Esta tipología de informes ha sido avalada como «un instrumento de cooperación mediante el cual la Comunidad Autónoma es llamada a intervenir en el curso de un procedimiento estatal a fin de hacer valer sus competencias e intereses, de principio afectados por el ejercicio de una competencia que corresponde, con todo, exclusivamente al Estado [...]. El trámite es preceptivo para el Estado, si bien el informe a emitir por la Comunidad Autónoma no es vinculante» (STC 155/2017, de 21 de diciembre, FJ 5..$^{\circ}$.

los conflictos. Quienes consideran que las deficiencias de nuestro Estado autonómico no provienen siempre, o solo, del contenido o la estructura del bloque de la constitucionalidad, sino también, en ocasiones, de la forma en que se interpreta ese bloque, obtendrán de la lectura de esta Sentencia respaldo a sus argumentos».

33 Díaz Revorio, op. cit., p. 311.

34 Tomamos la expresión del voto particular del magistrado Andrés Ollero Tassara a la STC 151/2017, de 21 de diciembre. En el mismo, se ensaya una clasificación de los supuestos más habituales de nulidad diferida en la jurisprudencia del Alto Tribunal: «Casos en los que se constataba que el legislador había omitido algún aspecto, lo que generaba la inconstitucionalidad de la norma (así, SSTC 138/2005, de 26 de mayo, y 273/2005, de 27 de octubre), o había incumplido un trámite procedimental inexcusable (SSTC 164/2013, de 26 de septiembre, 164/2014, de 7 de octubre, y 13/2015, de 5 de febrero, FJ 5 , por todas), o por inadecuación del instrumento normativo utilizado (SSTC 132/2010, de 2 de diciembre, y 164/2014, de 7 de octubre), o la inconstitucionalidad derivaba, no del contenido de la ley sino del incumplimiento de exigencias formales (SSTC 152/2014, de 25 de septiembre, FJ 6 b) 164/2014, de 7 de octubre, FJ 3) o de la imprevisión de aspectos materiales (STC 96/1996, de 30 de mayo, FJ 22 y 23)».

35 Díaz Revorio, op. cit., p. 311. 
e) Múltiples leyes del Estado han sido declaradas nulas por el Tribunal Constitucional al haberse omitido en su elaboración el «informe previo» que, para cualquier modificación del régimen especial de las Islas Canarias, exige la disposición adicional 3. ${ }^{a}$ de la Constitución de 1978. La STC 164/2013, de 26 de septiembre, y la STC 164/2014, de 7 de octubre, se insertan en esta senda jurisprudencial, pero con el matiz diferencial de emplear el expediente de la nulidad diferida "para cohonestar por un lado la exigencia procedimental del informe previo de la Comunidad Autónoma de Canarias, que viene establecida directamente por la Constitución, y, por otro, los intereses de los destinatarios de la norma, que podrían experimentar un perjuicio derivado de vacíos normativos» (STC 164/2014, de 7 de octubre, FJ 3. ${ }^{\circ}$ ).

f) La STC 13/2015, de 5 de febrero, sirvió para constatar que esta doctrina también resulta aplicable a otros supuestos en los que se exige un informe preceptivo autonómico, como ocurre con el art. 72.3 del Estatuto de Autonomía de Aragón. Mientras que la STC 155/2017, de 21 de diciembre, vino a frenar esta corriente al razonar que una norma de estas características «vincula, obviamente, a las instituciones y órganos del Estado en cada supuesto afectados. Pero también compromete a los titulares de este derecho de participación en orden a poner el debido celo en su ejercicio o a denunciar, llegado el caso, su merma en el curso del procedimiento en el que se padeció tal menoscabo. Si lo primero no se realizó, la ley, desde luego, no nació viciada [...]. Tampoco podría esperarse conclusión diferente, por lo demás, cuando no se reaccionó oportunamente frente a un proceder que, sin protesta previa alguna, se trae ante esta jurisdicción para solicitar la declaración de inconstitucionalidad de normas de ley» (FJ 8. ${ }^{\circ}$. 
